\title{
Fixing soft margins
}

\author{
Paul Kofman, Albert de Vaal and Casper G. de Vries*
}

Erasmus Universiteit Rotterdam, 3000 DR Rotterdam, Netherlands

Received March 1990, revised version received March 1992

Non-parametric tolerance limits are employed to calculate soft margins such as advocated in Williamson's target zone proposal. In particular, the tradeoff between softness and zone width is quantified. This may be helpful in choosing appropriate margins. Furthermore, it offers policymakers a framework for reference in the case of changing exchange rate policy. The empirical applications include an evaluation of the EMS zone width. We also show that the procedures for calculating the soft margins are robust against alternative data-generating mechanisms.

\section{Introduction}

In eliminating exchange rate misalignments a burden is placed upon the intervening country. Not only do these interventions exhaust the country's official reserves, but also subordinate domestic policy to achieving external balance. Therefore, with a managed float, a need exists to limit official intervention. For this reason Williamson (1985) proposes to set soft margins within which the real exchange rates are allowed to fluctuate. Unlike the rigid limits employed by, for example, the EMS, the soft margins occasionally may be exceeded. This can be a desirable property if governments are unable to precommit themselves to defending these margins at every price. Another argument in favor of soft rather than rigid margins is that it takes the wind out of the sails of speculators. That is, in taking positions speculators have to weigh the potential gain from a discrete realignment against the probability that authorities do not allow the exchange rate to move outside the zone and readjust the central rate smoothly. ${ }^{1}$

Correspondence to: C.G. de Vries, Internationale Economie, Erasmus Universiteit Rotterdam, P. Box 1738, 3000 DR Rotterdam, Netherlands.

*We are grateful to Filip Abraham, Paul De Grauwe, Henk Jager and Kees Koedijk for their stimulating comments, and Anna Kok for her lasting support. The comments and suggestions by two anonymous referees were highly valuable for improving the paper. We thank Kees Koedijk and Edith Siermann for making available their datasets.

${ }^{1}$ For a speculator to be willing to take a bet the odds ratio on a discrete realignment must exceed the inverse excess returns that accrues if a discrete realignment occurs [see, for example, Sargent (1987, ch. 7)]. A similar argument applies to Williamson's $(1985$, p. 65) example; see also Artis and Taylor (1990) and the formal arguments by Miller and Weller (1989) and Bertola and Caballero (1992). Krugman and Rotemberg (1992) discuss the relation between target zones and speculative attacks. 
There are several examples of currently existing soft margins. The divergence indicators that are employed by the EMS to signal a possible misalignment are, in effect, soft margins. When a rate crosses the so-called threshold of divergence, precautionary action can be undertaken but is not compulsory. ${ }^{2}$ Examples of soft margins can be found in other areas as well. Several stock exchanges and commodity boards employ trading limits which are invoked at the discretion of the floor's management [see, for example, Roll (1988)].

As it turns out, the determination of (soft) margins has received little attention in the literature. In the area of exchange rates the 2.25 percent margin currently employed by the EMS members is based upon the 2 percent rule of thumb that was originally proposed by Keynes with regard to the gold points and which was subsequently employed under the Bretton Woods arrangement. Williamson (1985) employs a large-scale macroeconomic model to calculate central rates and gauges that these calculations have a margin of error up to 10 percent. Given this uncertainty Williamson proposes the soft margins to be of the same magnitude, i.e. be as wide as 10 percent. Recently, Krugman and Rotemberg (1992) and Bertola and Caballero (1992) have solved explicitly for the exchange rate behavior in a partially credible band.

This solution can be used in principle to calculate the size of the band given a set of policy variables and restrictions. But again it presupposes quite detailed (econometric) knowledge about the working of the fundamentals. The aim of this paper is to investigate the uses of an alternativc way of fixing soft margins based on the simple non-parametric method of tolerance limits. This approach has certain advantages over the others.

The statistical theory on tolerance limits generates intervals that contain with probability $(1-\alpha)$ at least a certain percentage $\pi$ of the population. This directly operationalizes the idea behind soft margins since a percentage $(1-\pi)$ of the exchange rate realizations is allowed to be outside the soft margins. An advantage of this approach is that the softness of the margins is made explicit. This allows one to quantify the tradeoff that exists between the softness in terms of percentage exceedances and the zone width.

In estimating the margins that are consistent with the prevailing macro monetary policy regime, tolerance limits share the disadvantage with the macro approach, relied on by Williamson, that historical data must be used. Therefore the effects of new policy cannot be gauged in advance. As will become clear, however, the method is simple enough, such that it can be quickly applied to infer whether the desired margins and softness are compatible given a new set of policy actions. That is, from a limited sample

\footnotetext{
${ }^{2}$ These indicators are computed as follows: $0.75(1-w) * 0.0225 * \mathrm{ECU}$ rate, where $w$ is the share of the currency in the ECU and 0.0225 is the fluctuation margin; this margin was 0.06 in the case of the lira, and was lowered to 0.0225 in January 1990.
} 
of $n$ exchange rates and given the desired $(\alpha, \pi)$ configuration, the soft margins which are consistent with the policy undertaken are readily estimated. In section 3 this procedure is illustrated on the basis of the first 46 daily observations after the regime change of the Italian lira in January 1990. At this time the fluctuation margins of the lira were reduced to 2.25 percent. In case these new margins do not match the desired zone width, policy can be quickly readjusted. The large-scale macro approach is less well suited for such rapid feedback. To circumvent any misunderstanding, it is worth emphasizing that the method advanced in this paper does not generate policy-independent $(\alpha, \pi)$ configurations. But the gain is that new $(\alpha, \pi)$ combinations can be established relatively easily and rapidly after the introduction of a new exchange rate policy. A final advantage of employing tolerance limits is that certain questions, such as determining the sample size $n$, can be answered independently from the specific data-generating mechanism. This is a desirable property, given the endemic difficulties associated with modelling exchange rates; cf. Mussa (1979) and Meese and Rogoff (1983).

In the next section we briefly review the statistical theory of tolerance limits. On the basis of this theory we formulate a set of economic questions for which tolerance limits may be usefully employed. Section 3 contains the empirical counterpart of the theoretical section, which evaluates Williamson's proposal for stabilizing real rates and also focuses on the nominal rate arrangement of the EMS.

\section{Statistical theory and economic issues}

We start by reviewing the theory on tolerance intervals. Consider a random sample of independent random variables $X_{1}, \ldots, X_{n}$ from a common continuous distribution $F(\cdot)$ with density $f(\cdot){ }^{3}$ Define two distribution free statistics $L$ and $H$ called tolerance limits, such that the tolerance interval $(L, H)$ contains with probability $(1-\alpha)$ at least a percentage $\pi$ of the total population (tolerance limits should not be confused with confidence intervals). Formally, we seek statistics $L$ and $H$ such that

$$
\operatorname{Prob}\left\{\int_{L}^{H} f(x) \mathrm{d} x \geqq \pi\right\}=1-\alpha,
$$

where the distribution of $F(H)-F(L)$ does not depend on $F(\cdot)$. As it turns out, the latter requirement is satisfied if and only if $L$ and $H$ are chosen to be order statistics [see David $\left(1981\right.$, ch. 2.6)]. Letting $X_{(1)} \leqq \cdots \leqq X_{(m)} \leqq \cdots \leqq$

\footnotetext{
${ }^{3}$ The issue of dependent variates is discussed at the close of this section.
} 
$X_{(s)} \leqq \cdots \leqq X_{(n)}$ be the ascending order statistics, then there are values $(m, s)$ such that ${ }^{4}$

$$
\operatorname{Prob}\left\{F\left(X_{(s)}\right)-F\left(X_{(m)}\right) \geqq \pi\right\} \geqq 1-\alpha .
$$

In order to define one-sided tolerance limits the following convention is used: $X_{(m=0)}=-\infty$, and $X_{(s=n+1)}=\infty$. Also, it is sometimes more convenient to use the index $r$, which is implicitly defined through $n+1-r=s$, instead of the index $s$.

The non-parametric aspect of tolerance limits becomes evident from the following question. Given prescribed values for $(m, s)$ and $(\alpha, \pi)$, how large a sample $n$ must be taken to ascertain the inequalities in eq. (2)? Because $F\left(X_{(s)}\right)$ and $F\left(X_{(m)}\right)$ are just the order statistics corresponding to a uniform distribution, it is straightforward to show that $\alpha$ equals the incomplete beta function [see, for example, David (1981)]. Upon inversion the sample size $n$ can then be calculated. The following formula provides a good approximation [see, for example, Conover (1980, p. 118)]:

$$
n \simeq \frac{1}{4} \frac{1+\pi}{1-\pi} \chi_{(1-\alpha)}(2 m+2 r)+\frac{m+r-1}{2},
$$

where $\chi_{(1-\alpha)}(2 m+2 r)$ is the $(1-\alpha)$ th quantile from a chi-square random variable with $2 m+2 r$ degrees of freedom. Note that the size of the sample is determined independently of the specific distribution $F(\cdot)$ from which the data are generated. The value of the tolerance limits, though, still depends on the type of $F(\cdot)$ that applies.

An operational definition of softness and zone width is now easily given. On the basis of a sample of size $n$, the zone width is defined as the length of the tolerance interval $\left(X_{(m)}, X_{(s)}\right)$ that contains with probability $(1-\alpha)$ or higher at least a percentage $\pi$ of the total population. The softness of the zone consists in the percentage $(1-\pi)$ of the realizations that are allowed outside the zone. With these definitions and results in hand wc can address several economic issues.

Suppose a central bank has the objective to keep exchange rates or exchange rate returns within bounds. Given a policy prescribed $(\alpha, \pi)$ configuration, how large a sample should be taken to ascertain the feasibility of the objective? The answer can be found by applying formula (3). For example, let $(\alpha, \pi)=(0.05,0.90)$, with $m=r=1$ (i.e. $s=n)$. This gives $n=46$.

\footnotetext{
${ }^{4}$ Order statistics are defined as follows [see, for example, Conover $(1980$, p. 67)]. Let the variates from the random sample $X_{1}, \ldots, X_{n}$ be arranged in order of increasing magnitudes such that after relabeling, $X_{(1)} \leqq \cdots \leqq X_{(k)} \leqq \cdots \leqq X_{(n)}$, and we say that $X_{(k)}$ is the $k$ th ascending order statistic.
} 
Note that the sample size is independent from the specific $F(\cdot)$ that applies. Hence, with a change in the conduct of monetary policy like official intervention, a relatively short sample under the new policy rule already generates feasible soft margins; see section 3. The upper and lower bounds of the soft margins are identified with $X_{(m)}=X_{(1)}$ and $X_{(s)}=X_{(n)}$, respectively. The soft margins themselves, however, do depend on the specific $F(\cdot)$ and therefore on the policy rule which is in operation. Little is known about the link between exchange rates and monetary policy. This stems from two characteristics of the foreign exchange rate markets. Exchange rates are typically speculative prices which exhibit the unit root phenomenon [cf. Mussa (1979)], such that structural models do not contribute much in explaining their behavior [cf. Meese and Rogoff (1983)]. Central Banks, moreover, do not publicly announce their reaction functions which determine, for example, the amount of official intervention. ${ }^{5}$ It follows that the connection between monetary policy and the distribution function $F(\cdot)$ is merely a black box. For this reason it is important that credible margins can be determined relatively easily in a robust manner. Upon the presumption of a stable policy, we will investigate the size of the soft margins for two stabilization programs. This will be done in terms of the tradeoff between the softness and the size of the target zone. The two regimes constitute a fictitious program for real rates in the spirit of Williamson's proposal, and the evaluation of the divergence indicators in the EMS.

Under Williamson's target zone plan real rates are kept within soft margins while allowing for frequent adjustments of the central rates. Williamson goes as far as to suggest weekly realignments; we consider monthly adjustments. This is accomplished by investigating monthly real rate return data for currencies that have been more or less on a free float against each other. For a given sample size $n$ and probability level $\alpha=0.05$, different zone sizes are listed against the measure of softness $(1-\pi)$.

Given the policy pursued by the EMS countries, their bilateral nominal rates have been kept within the so-called fluctuation margins, while the occasional exceedances gave rise to a realignment of the central rates. Hence the nominal rates in deviation from the central rates are bounded statistics. ${ }^{6}$ These are used to evaluate the so-called divergence indicators. These

\footnotetext{
${ }^{5}$ This lack of precise knowledge notwithstanding, we do know something about the differences in exchange rate behavior under alternative exchange rate regimes. For example, Krugman and Rotemberg (1992) show that under a target zone arrangement the expectation that authorities will defend the band exerts a stabilizing effect, even when the authorities are not actively intervening; cf. footnote 1. The exchange rate movements within the band become S-shaped. Unfortunately, however, Meese and Rose (1990) and Flood, Rose and Mathieson (1991) are unable to detect this S-effect empirically.

${ }^{6} \mathrm{On}$ the basis of Dickey-Fuller tests non-stationarity was rejected for most exchange rates in deviation from their central rates at the 5 percent significance level. Non-stationarity, however, could not be rejected for the unadjusted rates, as anticipated.
} 
indicators constitute an inner multilateral margin, in contrast to the bilaterally defined fluctuation margins, and are supposed to function as an early warning system; see footnote 2 for a formal definition. 'The crossing of a divergence threshold entails the presumption, but not the obligation of corrective action by the authorities concerned' [Korteweg (1980, p. 30)]. These divergence indicators can therefore be interpreted as soft margins, and we quantify the amount of softness exhibited by the current system. On the one hand it appears that the divergence indicator has played only a limited role, mainly because the indicator's unfortunate multilateral definition signals the bilateral divergences in a distorted way [see, for example, Giavazzi and Giovannini (1989, p. 35)]. On the other hand, Giavazzi and Giovannini (1989, p. 65) show that intramarginal intervention represents a significant fraction of total intervention activities. Ungerer et al. (1986, p. 5) argue that early action in terms of intramarginal intervention lends credibility to the policy of trying to keep the exchange rates within the band, while allowing the exchange rate movements to gain momentum and resorting to marginal intervention alone tends to be destabilizing. Therefore we also consider a fictitious bilateral divergence indicator, in line with the bilateral nature of the fluctuation margins, which may have functioned as the de facto early warning system.

As outlined above, the size of the zone depends on $F(\cdot)$ and thereby upon the policy pursued. To investigate this dependency two different periods are considered for which it is known that the monetary authorities pursued different objectives, i.e. a different monetary policy for Germany. For each of these periods the above exercises are repeated and compared. In addition, the effect of the reduction in the fluctuation margin of the lira is studied separately.

Before turning to the empirical applications, we briefly address how dependency in the data affects the computation of the tolerance limits. Typically, exchange rate returns may exhibit some autocorrelation in the first moment, but the second moment is definitely autocorrelated, producing the typical periods of quiescence and turbulence [see, for example, Bollerslev (1990)]. While these types of dependencies still allow for consistent estimation of the tolerance limit, the small sample estimates can be less efficient. ${ }^{7}$ To investigate these matters we conducted several Monte Carlo experiments. As will become evident from the next section, the computation of tolerance limits does not seem to suffer much from the type of dependency usually encountered in exchange rate dala.

\footnotetext{
${ }^{7}$ Consistency of formula (2) for the i.i.d. case follows directly from the Glivenko-Cantelli theorem, which states that the empirical distribution converges in probability uniformly to the true distribution. This result carries over to dependent variates if $\left\{X_{i}\right\}$ is a strictly stationary stochastic process, e.g. an ARCH process [see Tucker (1959)]
} 


\section{Applications}

In this section we evaluate the tradeoff between the zone width and the softness for Williamson's target zone proposal and for the EMS thresholds of divergence. To this end, two different data sets are needed: one with real rates for the Williamson proposal, and one with nominal rates for the EMS. For the first application we constructed monthly real exchange rates for the British pound (BP), Dutch guilder (DG), Italian lira (IL) and Deutsche mark (DM) quoted against the United States dollar (US) over the period January 1973 to October 1987. The real rates are derived from the end-of-month spot rates and the respective wholesale price indices, all reported in the International Financial Statistics published by the International Monetary Fund. The real rates are computed as in McKinnon (1979, eq. 6.12). The real rates are then converted to monthly returns by taking logarithmic first differences. For the EMS application we used weekly Friday closing quotations of the Belgian franc (BF), French franc (FF), Danish krone (DK), Irish pound (IP), and the IL, DG and DM quoted against the US from the Harris bank. These quotations were then used to compute crossrates against the DM and the ECU. The sample covers the period 13 March 1979, i.e. the inception date of the EMS, to 6 February $1987 . .^{8}$ These nominal rates are then converted to relative deviations from the respective central rates. The thresholds are computed from the currency weights and parities against the ECU as reported in the EC bulletin. Finally, some daily data were collected to investigate the reduction in the fluctuation margin of the lira.

For the target zone proposal soft margins have to be established within which real rates fluctuate, while sometimes being allowed to move outside the band. One approach is to calculate bands on the basis of a macro model, cf. Williamson. This approach has the drawback of the presumed applicability of the structural equations and it does not easily make the softness cxplicit. The method of tolerance limits, on the other hand, does not rely on any structural relationship, but operationalizes the softness that is associated with the zone width. Table 1 provides the tradeoff between zone width and softness. ${ }^{9}$ The zone width is the difference, $X_{(s)}-X_{(m)}$, and the softness follows from eq. (3) upon inversion so that $1-\pi$ becomes explicit. The table provides the following information. For example, for a sample size $n=75$ the difference between the 71 st largest and 5th largest observation of the IL/US rate generates a zone width of $X_{(71)}-X_{(5)}=10.3$ and associated softness of $1-\pi=0.200$. To provide a yardstick for judging the zone width, the standard

\footnotetext{
${ }^{8}$ All data are available from the first author upon request.

${ }^{9}$ Calculations are based on data from a regime without a target zone. As explained before, the introduction of a target zone may affect $F(\cdot)$, cf. footnote 5 , and thus the estimates in table 1 may not be entirely applicable to a particular target zone. However, the method of tolerance limits is especially designed to quickly generate updated estimates once a new $(\alpha, \pi)$ configuration is chosen; see the example case of the lira which is discussed below.
} 
Table 1

The target zone proposal. ${ }^{2}$

\begin{tabular}{|c|c|c|c|c|c|c|}
\hline \multirow{2}{*}{$\begin{array}{l}\text { Sample } \\
\text { size }\end{array}$} & \multirow[b]{2}{*}{$r=m$} & \multirow{2}{*}{$\begin{array}{l}\text { Softness } \\
1-\pi\end{array}$} & \multicolumn{4}{|c|}{ Zone width } \\
\hline & & & $\mathrm{BP} / \mathrm{US}$ & $\mathrm{DG} / \mathrm{US}$ & IL/US & $\mathrm{DM} / \mathrm{US}$ \\
\hline$N=25$ & $\begin{array}{r}1 \\
2 \\
5 \\
10\end{array}$ & $\begin{array}{l}0.176 \\
0.282 \\
0.553 \\
0.947\end{array}$ & $\begin{array}{l}9.0 \\
6.2 \\
4.1 \\
0.9\end{array}$ & $\begin{array}{r}19.7 \\
11.2 \\
5.7 \\
1.4\end{array}$ & $\begin{array}{r}13.4 \\
10.8 \\
5.4 \\
2.4\end{array}$ & $\begin{array}{r}18.1 \\
16.1 \\
6.8 \\
1.8\end{array}$ \\
\hline$N=50$ & $\begin{array}{r}1 \\
2 \\
5 \\
10\end{array}$ & $\begin{array}{l}0.091 \\
0.147 \\
0.294 \\
0.512\end{array}$ & $\begin{array}{r}12.1 \\
8.7 \\
6.3 \\
4.6\end{array}$ & $\begin{array}{r}21.6 \\
14.9 \\
8.0 \\
4.5\end{array}$ & $\begin{array}{r}17.9 \\
13.1 \\
9.0 \\
4.3\end{array}$ & $\begin{array}{r}22.0 \\
18.6 \\
8.0 \\
5.6\end{array}$ \\
\hline$N=75$ & $\begin{array}{r}1 \\
2 \\
5 \\
10\end{array}$ & $\begin{array}{l}0.061 \\
0.100 \\
\underline{0.200} \\
0.350\end{array}$ & $\begin{array}{r}13.6 \\
2.1 \\
9.0 \\
6.2\end{array}$ & $\begin{array}{r}23.5 \\
21.2 \\
11.5 \\
7.2\end{array}$ & $\begin{array}{r}17.9 \\
13.9 \\
\frac{10.3}{5.0}\end{array}$ & $\begin{array}{r}22.6 \\
22.0 \\
9.6 \\
6.7\end{array}$ \\
\hline$N=100$ & $\begin{array}{r}1 \\
2 \\
5 \\
10\end{array}$ & $\begin{array}{l}0.046 \\
0.075 \\
0.151 \\
0.266\end{array}$ & $\begin{array}{r}17.2 \\
13.7 \\
10.8 \\
8.7\end{array}$ & $\begin{array}{r}23.9 \\
23.2 \\
13.9 \\
9.0\end{array}$ & $\begin{array}{r}19.8 \\
16.5 \\
11.8 \\
7.6\end{array}$ & $\begin{array}{r}24.1 \\
22.6 \\
13.1 \\
8.8\end{array}$ \\
\hline$N=125$ & $\begin{array}{r}1 \\
2 \\
5 \\
10\end{array}$ & $\begin{array}{l}0.037 \\
0.060 \\
0.122 \\
0.215\end{array}$ & $\begin{array}{l}17.2 \\
13.9 \\
11.9 \\
10.2\end{array}$ & $\begin{array}{r}23.9 \\
23.2 \\
13.9 \\
9.3\end{array}$ & $\begin{array}{r}19.8 \\
16.5 \\
11.9 \\
8.3\end{array}$ & $\begin{array}{r}24.1 \\
22.6 \\
13.1 \\
9.2\end{array}$ \\
\hline$N=150$ & $\begin{array}{r}1 \\
2 \\
5 \\
10\end{array}$ & $\begin{array}{l}0.031 \\
0.050 \\
0.102 \\
0.180\end{array}$ & $\begin{array}{l}23.8 \\
17.7 \\
12.4 \\
10.8\end{array}$ & $\begin{array}{l}23.9 \\
23.2 \\
12.3 \\
10.5\end{array}$ & $\begin{array}{r}19.8 \\
16.5 \\
12.4 \\
9.4\end{array}$ & $\begin{array}{l}24.1 \\
22.6 \\
14.9 \\
10.0\end{array}$ \\
\hline$N=175$ & $\begin{array}{r}1 \\
2 \\
5 \\
10\end{array}$ & $\begin{array}{l}0.026 \\
0.043 \\
0.088 \\
0.155\end{array}$ & $\begin{array}{l}23.8 \\
17.7 \\
12.4 \\
10.8\end{array}$ & $\begin{array}{l}23.9 \\
23.2 \\
15.6 \\
11.6\end{array}$ & $\begin{array}{l}19.8 \\
17.1 \\
13.1 \\
10.8\end{array}$ & $\begin{array}{l}24.1 \\
22.6 \\
14.9 \\
11.5\end{array}$ \\
\hline $\begin{array}{l}\text { Standard } \\
\text { deviation }\end{array}$ & & & 3.356 & 3.720 & 3.222 & 3.747 \\
\hline
\end{tabular}

${ }^{\text {a }}$ The $\alpha$ level is 0.05 . The $m$ and $r$ refer to the two order statistics which fix the tolerance limits. The zone widths and standard deviations are rescaled by a factor of 100 to turn these into percentages. The underlined figures are discussed in the text.

deviation of the real return is reported at the bottom of the table (the mean was never significantly different from zero). The softness and the zone width are inversely related, as expected. This inverse relationship, however, is not the same for all currencies. For example, both the BP/US and the DG/US rates have approximately the same zone for $1-\pi=0.512$ and $n=50$, but the DG/US rate requires a much wider zone for $1-\pi=0.091$. It also appears from the table that there is a tendency for those currencies that are closely kept in line with each other, i.e. the DG and DM, to require much larger 
Table 2

Frequency of threshold exceedances. ${ }^{a}$

(a) EMS definition

\begin{tabular}{|c|c|c|c|c|c|c|c|}
\hline \multirow{2}{*}{$\begin{array}{l}\text { Number } \\
\text { of weeks }\end{array}$} & \multicolumn{7}{|c|}{ Exceedances of EMS threshold } \\
\hline & $\mathrm{BF}$ & $\mathrm{FF}$ & IL & DG & DM & DK & IP \\
\hline 413 & $\begin{array}{l}175 \\
(42.4)\end{array}$ & $\begin{array}{l}124 \\
(30.3)\end{array}$ & $\begin{array}{l}31 \\
(7.5)\end{array}$ & $\begin{array}{l}132 \\
(32.0) \\
\end{array}$ & $\begin{array}{l}226 \\
(54.7) \\
\end{array}$ & $\begin{array}{l}137 \\
(33.2)\end{array}$ & $\begin{array}{l}104 \\
(25.2)\end{array}$ \\
\hline \multicolumn{8}{|c|}{ (b) Alternative definition } \\
\hline & $\mathrm{BF}$ & $F F$ & IL & DG & DM & DK & IP \\
\hline $\mathrm{BF}$ & - & $\begin{array}{l}155 \\
(37.5)\end{array}$ & $\begin{array}{l}47 \\
(11.4)\end{array}$ & $\begin{array}{l}128 \\
(31.0)\end{array}$ & $\begin{array}{l}120 \\
(29.1)\end{array}$ & $\begin{array}{l}107 \\
(25.9)\end{array}$ & $\begin{array}{l}87 \\
(21.1)\end{array}$ \\
\hline $\mathrm{FF}$ & $\begin{array}{l}149 \\
(36.1)\end{array}$ & - & $\begin{array}{l}3 \\
(0.7)\end{array}$ & $\begin{array}{c}44 \\
(10.7)\end{array}$ & $\begin{array}{l}100 \\
(24.2)\end{array}$ & $\begin{array}{c}42 \\
(10.2)\end{array}$ & $\begin{array}{l}36 \\
(8.7)\end{array}$ \\
\hline IL & $\begin{array}{l}40 \\
(9.7)\end{array}$ & $\begin{array}{c}3 \\
(0.7)\end{array}$ & - & $\begin{array}{l}22 \\
(5.3)\end{array}$ & $\begin{array}{l}26 \\
(6.3)\end{array}$ & $\begin{array}{l}9 \\
(2.2)\end{array}$ & $\begin{array}{c}4 \\
(1.0)\end{array}$ \\
\hline DG & $\begin{array}{l}124 \\
(30.0)\end{array}$ & $\begin{array}{c}45 \\
(10.9)\end{array}$ & $\begin{array}{l}23 \\
(5.6)\end{array}$ & - & $\begin{array}{l}24 \\
(5.8)\end{array}$ & $\begin{array}{c}69 \\
(16.7)\end{array}$ & $\begin{array}{c}76 \\
(18.4)\end{array}$ \\
\hline DM & $\begin{array}{l}117 \\
(28.3)\end{array}$ & $\begin{array}{l}99 \\
(24.0)\end{array}$ & $\begin{array}{l}27 \\
(6.5)\end{array}$ & $\begin{array}{l}25 \\
(6.1)\end{array}$ & - & $\begin{array}{c}84 \\
(20.3)\end{array}$ & $\begin{array}{c}98 \\
(23.7)\end{array}$ \\
\hline DK & $\begin{array}{l}102 \\
(24.7)\end{array}$ & $\begin{array}{c}44 \\
(10.7)\end{array}$ & $\begin{array}{l}18 \\
(4.4)\end{array}$ & $\begin{array}{c}69 \\
(16.7)\end{array}$ & $\begin{array}{c}85 \\
(20.6)\end{array}$ & - & $\begin{array}{l}31 \\
(7.5)\end{array}$ \\
\hline IP & $\begin{array}{c}84 \\
(20.3)\end{array}$ & $\begin{array}{l}37 \\
(9.0)\end{array}$ & $\begin{array}{l}4 \\
(1.0)\end{array}$ & $\begin{array}{l}77 \\
(18.6)\end{array}$ & $\begin{array}{c}96 \\
(23.2)\end{array}$ & $\begin{array}{l}31 \\
(7.5)\end{array}$ & - \\
\hline
\end{tabular}

${ }^{a}$ Exceedances of the 75 percent times 2.25 percent margins ( 6 percent for IL) of EMS exchange rates multilaterally (a) and bilaterally (b) between 13 March 1979 and 6 February 1987 (reported are the number of exceedances with the percentages in parentheses).

zone widths against the dollar for small $1-\pi$ vis-à-vis currencies that have a bad EMS reputation. Apparently, intra EMS stability is traded off against the stability of a currency against the dollar. This may, however, be an artifact due to small samples; cf. the lower part of the table. But note that estimates are relatively stable at different sample sizes. For example, the configuration $n=100$ and $1-\pi=0.046$ gives about the same zone widths as $n=175$ and $1-\pi=0.043$. In general, the zones required for low softness are quite high, i.e. of the order of magnitude of 20 percent as proposed by Williamson. A more modest softness of 10 percent reduces the required zone width to about 10 percent.

Within the EMS the exceedance of the divergence indicator by one of the currencies signals a possible upcoming exchange crisis which may be prevented by early action. The problem is, though, that the definition of an exchange rate crisis is in terms of the bilateral exchange rates, while the divergence indicators are in terms of the ECU. Thus, as has been noted in the literature, the alarm may not be in time, or false. Therefore we have computed the empirical frequency of exceedances of the 75 percent threshold by EMS currencies in two ways: see table 2 . The upper panel accords with 
the definition of the threshold employed by the EMS, the lower panel is in terms of bilateral currencies and is consistent with the definition of a crisis. Note that the lower panel is not completely symmetric due to Jensen's inequality. Roughly speaking, for all currencies on average once every month there is a week with a crossing of the divergence indicator. The exception is the IL due to its wider margins. From the lower panel it becomes clear that the DG and DM are a separate bloc in the EMS with relatively few crossings in terms of each other. This is not surprising given the policy pursued by the Dutch central bank.

In table 3 we have computed the tradeoff between the zone width implied by a divergence threshold and the softness for the EMS currencies. The computations for and the interpretations of the table are analogous to those of table 1. Note that the level of the threshold is inversely related to the timeliness of the warning. Thus, an alternative interpretation of table 3 is in terms of timeliness and softness. The underlined figures in part (a) correspond most closely to the current EMS defined threshold level, cf. footnote 2, and correspond to the alternative threshold level in part (b). In the latter case these are 9.00 for the IL, and 3.375 for the other currencies, respectively. In the former case these thresholds vary with the variation in the weights. Note that the softness associated with the actual EMS thresholds in table 3, part (a), corresponds very closely with the empirical frequencies reported in table 2, part (a). Table 3 offers policymakers the opportunity to gauge the effects of widening or narrowing these thresholds in terms of softness for the EMS arrangement.

As expected on the basis of table 3, for most currencies in part (a), the softness associated with the thresholds that are currently in operation is quite high, i.e. of the order of 35 percent. Exceptions are the IL and DM. The former is much lower owing to the wider margins for the lira, while the high softness of the mark can be explained by the fact that it is the $n$th and often strongest currency in the ECU basket. Therefore, if any other currency is low, then the DM is most likely carrying the reverse burden of being high. Thus, while it is not always the same currency that is low, the mark is usually the highest. In part (b) the alternative definition of the threshold of divergence is used for some selected currencies. The same zone width as in part (a) is now associated with a much lower softness. This is not too surprising given the fact that the alternative definition is in terms of bilateral exchange rates. A multilateral divergence occurs more frequently than a divergence for a given bilateral rate. In comparison with part (b), the part (a) also shows that somewhat higher multilateral thresholds, say a doubling of the zone width, would reduce the necessary softness dramatically. This indicates that the recurrent realignments during the first years of the EMS may have been a very high price for the narrow zone. Somewhat wider margins could potentially have reduced the pressure. 
Table 3

Fixing thresholds of divergence. ${ }^{2}$

(a) EMS definition

\begin{tabular}{|c|c|c|c|c|c|c|c|c|c|}
\hline \multirow{2}{*}{$\begin{array}{l}\text { Period: } \\
\text { Currency }\end{array}$} & \multicolumn{3}{|c|}{$\begin{array}{l}\text { 13.3.1979-5.1.1987 } \\
(n=409 \text { weeks })\end{array}$} & \multicolumn{3}{|c|}{$\begin{array}{l}13.3 .1979-10.7 .1981 \\
(n=122 \text { weeks })\end{array}$} & \multicolumn{3}{|c|}{$\begin{array}{l}21.3 .1983-15.7 .1985 \\
(n=122 \text { weeks })\end{array}$} \\
\hline & $r=m$ & $1-\pi$ & Zone & $r=m$ & $1-\pi$ & Zone & $r=m$ & $1-\pi$ & Zone \\
\hline $\mathrm{BF}$ & $\begin{array}{r}1 \\
10 \\
15 \\
25 \\
50 \\
73 \\
100\end{array}$ & $\begin{array}{l}0.011 \\
0.066 \\
0.095 \\
0.150 \\
0.280 \\
\underline{0.397} \\
0.531\end{array}$ & $\begin{array}{l}7.78 \\
6.19 \\
5.28 \\
4.62 \\
3.65 \\
3.07 \\
2.40\end{array}$ & $\begin{array}{r}1 \\
10 \\
\frac{12}{15} \\
25\end{array}$ & $\begin{array}{l}0.038 \\
0.220 \\
0.257 \\
0.311 \\
0.483\end{array}$ & $\begin{array}{l}4.80 \\
3.42 \\
2.92 \\
2.55 \\
1.44\end{array}$ & $\begin{array}{r}1 \\
10 \\
15 \\
\frac{25}{30}\end{array}$ & $\begin{array}{l}0.038 \\
0.220 \\
0.311 \\
0.483 \\
0.566\end{array}$ & $\begin{array}{l}5.11 \\
4.04 \\
3.82 \\
3.08 \\
2.64\end{array}$ \\
\hline $\mathrm{FF}$ & $\begin{array}{r}1 \\
10 \\
15 \\
25 \\
50 \\
\frac{69}{100}\end{array}$ & $\begin{array}{l}0.011 \\
0.066 \\
0.095 \\
0.150 \\
0.280 \\
\underline{0.376} \\
0.531\end{array}$ & $\begin{array}{l}7.11 \\
5.63 \\
5.03 \\
4.39 \\
3.43 \\
2.75 \\
1.94\end{array}$ & $\begin{array}{r}1 \\
\frac{9}{10} \\
15\end{array}$ & $\begin{array}{l}0.038 \\
0.202 \\
0.220 \\
0.311\end{array}$ & $\begin{array}{l}3.83 \\
2.65 \\
2.55 \\
2.17\end{array}$ & $\begin{array}{r}1 \\
\frac{8}{10} \\
15\end{array}$ & $\begin{array}{l}0.038 \\
0.183 \\
0.220 \\
0.311\end{array}$ & $\begin{array}{l}6.03 \\
2.77 \\
2.59 \\
2.32\end{array}$ \\
\hline IL & $\begin{array}{r}1 \\
10 \\
15 \\
\frac{16}{25} \\
50\end{array}$ & $\begin{array}{l}0.011 \\
0.066 \\
0.095 \\
0.101 \\
0.150 \\
0.280\end{array}$ & $\begin{array}{r}11.22 \\
9.50 \\
8.36 \\
8.19 \\
7.47 \\
5.00\end{array}$ & $\begin{array}{r}1 \\
6 \\
10 \\
15\end{array}$ & $\begin{array}{l}0.038 \\
0.145 \\
0.220 \\
0.311\end{array}$ & $\begin{array}{l}8.90 \\
8.17 \\
7.05 \\
6.32\end{array}$ & $\begin{array}{r}1 \\
2 \\
10 \\
15\end{array}$ & $\begin{array}{l}0.038 \\
0.062 \\
0.220 \\
0.311\end{array}$ & $\begin{array}{r}10.00 \\
7.15 \\
4.93 \\
4.46\end{array}$ \\
\hline DG & $\begin{array}{r}1 \\
10 \\
15 \\
25 \\
50 \\
66 \\
\frac{75}{75} \\
100\end{array}$ & $\begin{array}{l}0.011 \\
0.066 \\
0.095 \\
0.150 \\
0.280 \\
0.361 \\
0.407 \\
0.531\end{array}$ & $\begin{array}{l}7.54 \\
6.21 \\
5.46 \\
4.43 \\
3.58 \\
3.02 \\
2.67 \\
1.89\end{array}$ & $\begin{array}{r}1 \\
4 \\
10 \\
15\end{array}$ & $\begin{array}{l}0.038 \\
0.105 \\
0.220 \\
0.311\end{array}$ & $\begin{array}{l}3.34 \\
3.02 \\
2.45 \\
2.12\end{array}$ & $\begin{array}{r}1 \\
4 \frac{4}{0} \\
15\end{array}$ & $\begin{array}{l}0.038 \\
0.105 \\
0.220 \\
0.311\end{array}$ & $\begin{array}{l}3.42 \\
\frac{3.07}{2.54} \\
2.35\end{array}$ \\
\hline DM & $\begin{array}{r}1 \\
10 \\
15 \\
25 \\
50 \\
75 \\
\frac{105}{125}\end{array}$ & $\begin{array}{l}0.011 \\
0.066 \\
0.095 \\
0.150 \\
0.280 \\
0.407 \\
0.556 \\
0.654\end{array}$ & $\begin{array}{l}9.61 \\
7.46 \\
6.25 \\
5.23 \\
4.12 \\
3.28 \\
2.20 \\
1.72\end{array}$ & $\begin{array}{r}1 \\
10 \\
15 \\
\frac{24}{30}\end{array}$ & $\begin{array}{l}0.038 \\
0.220 \\
0.311 \\
0.467 \\
0.566\end{array}$ & $\begin{array}{l}5.93 \\
3.87 \\
3.33 \\
\frac{2.24}{1.93}\end{array}$ & $\begin{array}{r}1 \\
10 \\
15 \\
\frac{28}{30}\end{array}$ & $\begin{array}{l}0.038 \\
0.220 \\
0.311 \\
0.534 \\
0.566\end{array}$ & $\begin{array}{l}4.12 \\
3.40 \\
3.02 \\
2.26 \\
2.11\end{array}$ \\
\hline DK & $\begin{array}{r}1 \\
10 \\
15 \\
50 \\
\frac{63}{75}\end{array}$ & $\begin{array}{l}0.011 \\
0.066 \\
0.095 \\
0.280 \\
0.346 \\
0.407\end{array}$ & $\begin{array}{l}9.01 \\
5.86 \\
5.48 \\
3.87 \\
\frac{3.30}{2.96}\end{array}$ & $\begin{array}{r}1 \\
10 \\
15 \\
\frac{16}{25}\end{array}$ & $\begin{array}{l}0.038 \\
0.220 \\
0.311 \\
0.328 \\
0.483\end{array}$ & $\begin{array}{l}5.86 \\
3.89 \\
3.41 \\
\frac{3.25}{2.40}\end{array}$ & $\begin{array}{r}1 \\
10 \\
15 \\
\frac{22}{25}\end{array}$ & $\begin{array}{l}0.038 \\
0.220 \\
0.311 \\
\underline{0.432} \\
0.483\end{array}$ & $\begin{array}{r}5.65 \\
4.24 \\
3.92 \\
3.29 \\
3.16\end{array}$ \\
\hline IP & $\begin{array}{r}1 \\
10 \\
15 \\
25 \\
49 \\
50 \\
75\end{array}$ & $\begin{array}{l}0.011 \\
0.066 \\
0.095 \\
0.150 \\
0.275 \\
0.280 \\
0.407\end{array}$ & $\begin{array}{l}7.98 \\
6.09 \\
5.26 \\
4.40 \\
3.36 \\
3.32 \\
2.70\end{array}$ & $\begin{array}{r}1 \\
10 \\
\frac{11}{15}\end{array}$ & $\begin{array}{l}0.038 \\
0.220 \\
0.239 \\
0.311\end{array}$ & $\begin{array}{r}6.22 \\
3.84 \\
\frac{3.35}{2.60}\end{array}$ & $\begin{array}{r}1 \\
10 \\
\frac{16}{20}\end{array}$ & $\begin{array}{l}0.038 \\
0.220 \\
0.328 \\
0.398\end{array}$ & $\begin{array}{l}5.69 \\
3.66 \\
3.29 \\
3.06\end{array}$ \\
\hline
\end{tabular}


Table 3-Continued

(b) Alternative definition (selected currencies)

\begin{tabular}{|c|c|c|c|c|c|c|c|c|c|}
\hline \multirow{2}{*}{$\begin{array}{l}\text { Period: } \\
\text { Currency }\end{array}$} & \multicolumn{3}{|c|}{$\begin{array}{l}13.3 .1979-5.1 .1987 \\
(n=409 \text { weeks })\end{array}$} & \multicolumn{3}{|c|}{$\begin{array}{l}13.3 .1979-10.7 .1981 \\
(n=122 \text { weeks })\end{array}$} & \multicolumn{3}{|c|}{$\begin{array}{l}21.3 .1983-15.7 .1985 \\
(n=122 \text { weeks })\end{array}$} \\
\hline & $r=m$ & $1-\pi$ & Zone & $r=m$ & $1-\pi$ & Zone & $r=m$ & $1-\pi$ & Zone \\
\hline \multirow[t]{6}{*}{ DG/DM } & 1 & 0.011 & 5.06 & 1 & 0.038 & 4.21 & 1 & 0.038 & 2.45 \\
\hline & 5 & 0.038 & 3.52 & 5 & 0.125 & 3.51 & 5 & $\overline{0.125}$ & $\overline{1.27}$ \\
\hline & $\underline{6}$ & $\underline{0.044}$ & 3.45 & & & & & & \\
\hline & & & & $\underline{8}$ & 0.183 & 3.36 & 8 & 0.183 & 1.17 \\
\hline & 10 & 0.066 & 3.28 & $1 \overline{0}$ & $\overline{0.220}$ & 3.27 & 10 & 0.220 & 1.07 \\
\hline & 15 & 0.095 & 3.02 & 15 & 0.311 & 2.98 & 15 & 0.311 & 0.86 \\
\hline \multirow[t]{3}{*}{$\mathrm{DG} / \mathrm{BF}$} & 1 & 0.011 & 4.27 & 1 & $\underline{0.038}$ & 2.67 & 1 & $\underline{0.038}$ & 3.01 \\
\hline & $\frac{5}{n}$ & 0.038 & $\frac{3.38}{202}$ & & & & & & \\
\hline & 15 & $\begin{array}{l}0.095 \\
0.095\end{array}$ & $\begin{array}{l}3.03 \\
2.76\end{array}$ & 15 & $\begin{array}{l}0.220 \\
0.311\end{array}$ & $\begin{array}{l}1.00 \\
1.65\end{array}$ & 15 & $\begin{array}{l}0.220 \\
0.311\end{array}$ & 2.53 \\
\hline \multirow{6}{*}{$\mathrm{DG} / \mathrm{FF}$} & 1 & 0.011 & 8.26 & 1 & 0.038 & 3.12 & 1 & 0.038 & 4.58 \\
\hline & & & & $\overline{2}$ & $\overline{0.062}$ & $\overline{2.88}$ & 2 & 0.062 & 2.76 \\
\hline & 10 & 0.066 & 3.95 & 10 & 0.220 & 1.37 & $1 \overline{0}$ & $\overline{0.220}$ & 2.03 \\
\hline & 15 & 0.095 & 3.63 & 15 & 0.311 & 1.10 & 15 & 0.311 & 1.59 \\
\hline & 23 & 0.139 & 3.37 & & & & & & \\
\hline & $\overline{25}$ & $\overline{0.150}$ & $\overline{3.27}$ & & & & & & \\
\hline \multirow[t]{5}{*}{$\mathrm{DM} / \mathrm{IL}$} & 1 & 0.011 & 12.26 & 1 & 0.038 & 9.53 & 1 & 0.038 & 11.68 \\
\hline & & & & $\overline{2}$ & $\overline{0.062}$ & 6.81 & $\underline{2}$ & 0.062 & $\underline{8.91}$ \\
\hline & 5 & 0.038 & 9.12 & & & & & & \\
\hline & $\underline{6}$ & $\underline{0.044}$ & 8.99 & & & & & & \\
\hline & $1 \overline{0}$ & $\overline{0.066}$ & $\overline{8.63}$ & 10 & 0.220 & 4.70 & 10 & 0.220 & 7.44 \\
\hline \multirow[t]{7}{*}{ FF/DM } & 1 & 0.011 & 9.13 & 1 & 0.038 & 4.91 & 1 & 0.038 & 6.36 \\
\hline & & & & & & & $\underline{2}$ & 0.062 & 3.47 \\
\hline & & & & 5 & 0.125 & 3.97 & $\overline{5}$ & $\overline{0.125}$ & $\overline{2.78}$ \\
\hline & & & & $\underline{9}$ & 0.202 & 3.31 & & & \\
\hline & 10 & 0.066 & 4.36 & $1 \overline{0}$ & 0.220 & 2.99 & 10 & 0.220 & 2.43 \\
\hline & 25 & 0.150 & 3.93 & & & & & & \\
\hline & $\underline{34}$ & $\underline{0.197}$ & $\underline{3.36}$ & & & & & & \\
\hline \multirow[t]{5}{*}{$\mathrm{FF} / \mathrm{IL}$} & 1 & 0.011 & 10.33 & $\underline{1}$ & 0.038 & 9.56 & 1 & 0.038 & 10.33 \\
\hline & & & & $\overline{2}$ & $\overline{0.062}$ & 7.25 & $\underline{2}$ & $\underline{0.062}$ & 7.85 \\
\hline & $\underline{3}$ & $\underline{0.026}$ & 8.52 & & & & & & \\
\hline & $1 \overline{0}$ & $\overline{0.066}$ & 7.30 & 10 & 0.220 & 6.52 & 10 & 0.220 & 5.90 \\
\hline & 15 & 0.095 & 6.97 & 15 & 0.311 & 6.18 & 15 & 0.311 & 5.42 \\
\hline
\end{tabular}

${ }^{a}$ The $\alpha$ level is 0.05 , and the zone widths again are rescaled by a factor of 100 . The interpretation of the table is analogous to that of table 1.

Columns 2 and 3 in both parts of table 3 show the results for two subperiods of equal length. These periods were characterized by respectively a contractionary and expansionary monetary policy in Germany [see Ungerer et al. (1986)]. Therefore, a comparison between the two subperiods, and a comparison with the results for the entire period, indicate the stability of the results. Potentially, different policy regimes generate different zone width and softness combinations. From the parts (a) and (b) it appears that 
Table 4

Fixing thresholds of divergence after policy change. ${ }^{a}$

(a) EMS definition

\begin{tabular}{|c|c|c|}
\hline & \multicolumn{2}{|c|}{ Zone width } \\
\hline & $\begin{array}{l}\text { Daily } \\
(1990)\end{array}$ & $\begin{array}{l}\text { Weekly } \\
(1979-1980)\end{array}$ \\
\hline BF & 0.89 & 1.53 \\
\hline FF & 0.93 & 1.52 \\
\hline IL & 0.91 & 4.68 \\
\hline DG & 0.84 & 1.21 \\
\hline $\mathrm{DM}$ & 1.28 & 2.56 \\
\hline \multicolumn{3}{|c|}{ (b) Alternative definition } \\
\hline $\mathrm{DG} / \mathrm{DM}$ & 1.19 & 2.61 \\
\hline $\mathrm{DG} / \mathrm{BF}$ & 1.13 & 2.19 \\
\hline $\mathrm{DG} / \mathrm{FF}$ & 0.78 & 1.50 \\
\hline $\mathrm{DM} / \mathbf{I L}$ & 1.70 & 3.70 \\
\hline $\mathrm{FF} / \mathrm{DM}$ & 2.15 & 2.20 \\
\hline $\mathrm{FF} / \mathrm{IL}$ & 2.25 & 4.67 \\
\hline \multicolumn{3}{|c|}{$\begin{array}{l}{ }^{a} \text { Computations are based on daily rates } \\
\text { over the period }(15.01 .90-20.03 .90) \text { and } \\
\text { weekly rates over the period }(30.11 .79 \\
11.10 .80) \text {. The following parameter values } \\
\text { were used: } n=46, \quad r=m=1, \quad \alpha=0.05 \text { and } \\
1-\pi=0.10 \text {. }\end{array}$} \\
\hline
\end{tabular}

the two subperiods are very similar, and have zone-softness combinations that are of the same order of magnitude as for the entire period. There are two exceptions to the similarity in subperiods: the DG/DM and FF/DM rates had much lower softness during the second subperiod. Most likely this stems from the loosening of monetary policy (i.e. a loosening of the credit market) during the second period in Germany.

An interesting regime switch occurred on 8 January 1990 when the fluctuation margins of the lira were reduced from 6 to 2.25 percent. We investigate this policy change for two reasons. First, the regime switch was much more apparent to the public than the other two considered above. Secondly, it provides a nice opportunity to demonstrate the rapid feedback generated by the tolerance limits. To this end we collected 46 daily rates from the Wall Street Journal for the period 15 January to 20 March 1990. Over this period the lira was outside the EMS threshold of divergence for 17 percent of the time. Table 4 reports the zone widths that are associated with a softness $1-\pi=0.10$ and an $\alpha$ level of 0.05 . All zones are smaller than the actual zone widths (recall that these are 3.375 for the alternative definition).

It appears that the chosen softness is compatible with the zone widths. The margins might even be somewhat reduced. To provide material for compari- 
Table 5

Effects of dependency. ${ }^{2}$

\begin{tabular}{llcc}
\hline & Independent & AR(1) & GARCH $(1,1)$ \\
\hline $1-\pi$ (mean) & 0.073 & 0.077 & 0.081 \\
$1-\pi$ (max) & 0.127 & 0.123 & 0.140 \\
$1-\pi$ (min) & 0.037 & 0.042 & 0.030 \\
$1-\pi$ (s.d.) & 0.014 & 0.014 & 0.018 \\
Zone (mean) & 3.544 & 3.563 & 3.513 \\
Zone (max) & 4.124 & 4.087 & 4.417 \\
Zone (min) & 3.006 & 3.081 & 2.936 \\
Zone (s.d.) & 0.155 & 0.170 & 0.219 \\
$\alpha$ & 2.100 & 5.400 & 14.900 \\
\hline
\end{tabular}

${ }^{a}$ The following AR(1) scheme was used in generating dependent data: $X_{t}=0.1 X_{t-1}+e_{t}$, where the $e_{t}$ are independent standard normally distributed. The GARCH $(1,1)$ process used was: $X_{t}=e_{t} v_{t}, v_{t}^{2}=0.03+0.02 x_{t-1}^{2}+0.95 v_{t-1}^{2}$, where again the $e_{t}$ are i.i.d. standard normal.

son, we also computed the zone width using the weekly data over the period November 1979 to October 1980. This period was the first period containing at least 46 consecutive weeks without a realignment. The more recent daily zone widths reveal the convergence which has been achieved by the EMS.

To further investigate the robustness of our results, we studied the effects of serial dependency. The Box-Ljung test statistic indicates some autocorrelation in the first moment of most currency returns, but autocorrelation coefficients were always smaller than 0.1. ARCH effects, however, indicating serial dependency in the second moment, were strongly present in the weekly series. Evidence on this effect is well reported in the literature [see, for example, Bollerslev (1990)], and is not repeated here to save space. In order to investigate the effects of these types of autocorrelation on our procedures we conducted some Monte Carlo experiments. In table 5 an independently normally distributed dataset is compared with two explicitly dependent datasets. We consider two stochastic processes: AR(1) with autoregressive parameter 0.1, and GARCH $(1,1)$ with standard normal innovations and volatility function $v_{t}^{2}=a+b x_{t-1}^{2}+d v_{t-1}^{2}$, where $x_{t}$ are the realizations and $v_{t}$ are the conditional variances, and parameter values $a=0.03, b=0.02, d=0.95$ [these values are similar to those that are reported by, for example, Bollerslev (1990)]. The parameters are chosen such that unconditional variances of the i.i.d. series, the $\operatorname{AR}(1)$ and the $\operatorname{GARCH}(1,1)$ process, are of comparable magnitudes. From a 1,000 times repeated drawing of a random sample of size $n=409$, the mean, minimum, maximum and standard deviation values for softness and zone width were computed. It appears from table 5 that dependency does not significantly influence the results. But the 
precision is decreased, i.e. $\alpha$ increases, as was anticipated at the end of section 2.

\section{Conclusions}

The tolerance limit approach advocated in this paper offers an attractive framework to policymakers on two accounts. First, the tradeoff that exists between softness and zone width is quantified explicitly. To the best of our knowledge, this has not been investigated in the literature before. Second, even though the analysis relies on historical data, it is flexible enough to quickly check whether the desired margins and softness are in line with each other. Unlike extensive macro models, it provides the swiftness and robustness often sought for when testing for consistency in exchange rate policy.

\section{References}

Artis, M.J. and M.P. Taylor, 1990, International financial stability and the regulation of capital flows, in: G. Bird, ed., The international financial regime (Surrey University Press, London) 163-196.

Bertola, G. and R.J. Caballero, 1992, Sustainable intervention policies and exchange rate dynamics, in: P. Krugman and M. Miller, eds., Exchange rate targets and currency bands (Cambridge University Press, Cambridge) 186-206.

Bollerslev, T., 1990, Modeling the coherence in short-run nominal exchange rates: A multivariate generalized ARCH-model, The Review of Economics and Statistics 72, 498-505.

Conover, W.J., 1980, Practical nonparametric statistics, 2nd cdn. (Wilcy, New York).

David, H.A., 1981, Order statistics, 2nd edn. (Wiley, New York).

Flood, R.P., A.K. Rose and D.J. Mathieson, 1991, An empirical exploration of exchange rate target-zones, NBER Working Paper 3543.

Giavazzi, F. and A. Giovannini, 1989, Limiting exchange rate flexibility (MI'T Press, Cambridge, MA).

Korteweg, P., 1980, The European monetary system - will it really bring more monetary stability to Europe?, De Economist 128, 15-49.

Krugman, P. and J. Rotemberg, 1992, Speculative attacks on target zones, in: P. Krugman and M. Miller, eds., Exchange rate targets and currency bands (Cambridge University Press, Cambridge) $177-232$.

McKinnon, 1979, Money in international exchange (Oxford University Press, New York).

Meese, R. and K. Rogoff, 1983, Empirical exchange rate models of the seventies: Do they fit out of sample?, Journal of International Economics 14, 3-24.

Meese, R.A. and A.K. Rose, 1990, Nonlinear, nonparametric, nonessential exchange rate estimation, American Economic Review 80, 192-196.

Miller, M. and P. Weller, 1989, Exchange rate bands and realignments in a stationary stochastic setting, in: M. Miller, B. Eichengreen and R. Portes, eds., Blueprints for exchange-rate management (Academic Press, London) 161-173.

Mussa, M., 1979, Empirical regularities in the behavior of exchange rates and theories of the foreign exchange market, Carnegie-Rochester Conference Series on Public Policy, 9-57.

Roll, R., 1988, The international crash of October 1987, Financial Analyst Journal 44, no. 5, 19-35. 
Sargent, T.J., 1987, Macroeconomic theory, 2nd edn. (Academic Press, Boston, MA).

Tucker, H.G., 1959, A generalization of the Glivenko-Cantelli theorem, Annals of Mathematical Statistics 30, 828-830.

Ungerer, H., O. Evans, T. Mayer and P. Young, 1986, The European monetary system: Recent developments, Occasional IMF Papers, no. 48.

Williamson, J., 1985, The exchange rate system, 2nd edn. (Institute for International Economics, Washington, DC). 